\title{
HUMAN BEHAVIOUR IN TIMES OF CRISIS. ANTHROPOLOGICAL AND SOCIOLOGICAL INSIGHTS
}

\author{
Sergiu B $\breve{A L A N}{ }^{a^{*}}$, Lucia Ovidia VREJA ${ }^{b}$ \\ ${ }^{a, b}$ Bucharest University of Economic Studies, Romania
}

\begin{abstract}
One of the constants of our species' history is the fact that from time to time people find themselves in the situation of being forced to cope with events that put a great amount of pressure on certain aspects of humanity's existence, or even endanger this very existence. Due to the deeply disturbing nature of these situations, we call them crises, and one of them, generated by the COVID-19 pandemic, is right now in full swing. How humanity reacts in these circumstances is of the utmost importance. For this reason, in our paper we tried to argue that people should not give in to the urge to act driven by panic or by inappropriate ideas about the nature of the ongoing phenomenon. One of the most dangerous ideas is that a crisis is first and foremost an opportunity, a welcomed occasion for a possible 'reset' of the very society as a whole. We then tried to argue that any reaction to the ongoing crisis must be based on a correct understanding of the phenomenon, both as a whole, but also in its details. For this reason, believing that anthropology and sociology can provide fundamental insights, appropriate perspectives for investigation and useful factual information, we have provided in the article some insights from the point of view of these disciplines to help shape this understanding of the ongoing crisis.
\end{abstract}

KEYWORDS: COVID-19, crisis, inclusion, ostracism, pandemics, social distance.

DOI: $10.24818 / \mathrm{IMC} / 2021 / 05.13$

\section{INTRODUCTION}

Beyond the economic and medical aspects, which are not to be neglected, the COVID-19 pandemic is a deeply social crisis (Matthewman \& Huppatz, 2020), which has left its mark on all aspects that we include, generically, in the concept of "social human nature". First of all, epidemiological crises are essentially social phenomena because their range is extended to a large group of people and they are never experienced individually. Precisely the essentially social core of human nature, i.e., people's natural tendency towards association and interaction, is the motive that brings them together and thus makes possible the spread of the virus. Secondly, the identification and, especially, the implementation of measures to overcome the medical crisis requires a correct knowledge of the cultural elements that underlie people's beliefs and behaviours, but also collective efforts and common actions, any individual approach being doomed to failure.

While there is an extended literature on various aspects of the COVID-19 pandemic that approaches the problems from the perspective of a wide range of disciplines, among which economic and medical sciences play a prominent role, the social aspects of this "novel" crisis seem rather undervalued. The paper is an attempt to bring into attention some facets of human behaviour, such as resistance to change and need to belong, or cultural and social practices and atavistic believes, that might be the key to disease control.

\footnotetext{
${ }^{*}$ Corresponding author. E-mail address: sergiu.balan@man.ase.ro
} 


\section{THE CRISIS: DANGER OR OPPORTUNITY?}

\subsection{General conceptual considerations}

At the beginning of their book on the COVID-19 pandemic and the prospects for human society to return to a normal state of affairs after the end of this crisis, Fons Trompenaars and Charles Hampden-Turner, the authors of the best-known conceptual frame of cross-cultural analysis of organizational behaviour and organizational management, which we discussed at length in a previously published study (Bălan \& Vreja, 2013), argue in an extremely pragmatic way in favour of Paul Romer's idea that a major crisis is a too important social and economic phenomenon to be allowed to pass without effectively exploiting all the opportunities it offers (Trompenaars \& Hampden-Turner, 2021). In order to give this idea a more suggestive character, they make reference, in a way in which (given the initial source of the SARS-CoV-2 virus infection) an involuntary irony occurs, to the Chinese ideogram that signifies the concept of 'crisis', arguing that: "The Chinese word for 'crisis' is 'danger-opportunity', two characters juxtaposed" (Trompenaars \& Hampden-Turner, 2021: 1).

Unfortunately for the beauty of the argument, this etymological explanation is nothing more than a fantasy, and we are dealing here with an 'urban myth' that prevailed in public discourse since its first use in 1959 by John F. Kennedy, in a speech delivered at United Negro College Fund, Indianapolis, where he said: "When written in Chinese, the word crisis is composed of two characters. One represents danger and the other represents opportunity" (Shapiro, 2006: 420). Many other American public figures, including Al Gore and Condoleezza Rice, took over the idea without first checking its accuracy and used it in their speeches, due to its formidable rhetorical effect, which could rather indicate something about the Western mentality, than about the Chinese thinking. We must not forget that American philosophical doctrine par excellence is pragmatism, and in this context the truth and meaning of a concept are reduced to nothing else but the totality of the consequences of its application in practical activity (Hookway, 1992), as explicitly stated by one of the founders of this philosophical school, Charles Sanders Peirce: "In order to ascertain the meaning of an intellectual conception one should consider what practical consequences might conceivably result from necessity from the truth of that conception; and the sum of these consequences will constitute the entire meaning of the conception" (Peirce, 1935: vol. 5, § 9).

However, the ideal of scientific accuracy forces us to point that according to the opinion of important sinologists, the interpretation of the ideogram in the abovementioned manner is an erroneous one. Thus, the ideogram for the concept of 'crisis' (wei iji $)$ is indeed composed of two characters, $w \bar{e} i$ and $j \bar{l}$, but if the former can have the meaning of 'danger', the latter does not mean 'opportunity' at all, but rather "incipient moment; crucial point (when something begins or changes)." Consequently, weijī does not refer to a dangerous moment that on the other hand brings a lot of opportunities we should take advantage of without hesitation, but designates a situation full of dangers, in which we need to be careful and expect unforeseen things and important changes to happen (Mair, 2009).

All these considerations must not, however, lead us to set aside entirely the hermeneutic suggestion made, in a rather unscientific and superficial way, by Trompenaars and Hampden-Turner, who have proven unable to resist the temptation of rhetorical effects. Rather, we believe that we should keep in mind the idea that before rushing to act and exploit hypothetical opportunities, we need a moment of reflection and clarification of ideas about what is in fact happening in these times of crisis in the whole world, so that the decisions regarding our subsequent actions are based on a more correct understanding of reality, and not on slogans and wishful thinking. So, what can be said about what is happening in the context of the COVID-19 pandemic and the ways it affects us all, either directly or through its generic social effects? 


\subsection{The current crisis and "COVID society"}

As Deborah Lupton and Karen Willis argue, the current epidemiological crisis is nothing short of a phenomenon that has radically transformed the entire world into what they call a "global COVID society", which means that we are not dealing with a simple medical problem of great magnitude but with a crisis that encompasses all levels and forms of human life. The crisis is a problem of ecology (since the source of the virus is non-human, it concerns the relationship between humans and other species), but also one of social organization, as it affects the very functioning of the fundamental structures of human society. It is also a matter of individual and collective psychology, a cultural and religious issue, a scientific and technological one, but nonetheless an economic and political one (Lupton \& Willis, 2021b: 3-4).

It seems that no area of human life has escaped untouched, and in the fall of 2021 the phenomenon is still far from over. Phenomena such as forced quarantine, limitation of social interactions, physical distancing, isolation inside homes, border closures, closure and bankruptcy of many companies, job loss, online work, online education, restriction of freedoms, limited opportunities to travel and spending leisure time, changing of interpersonal relationships, such as family relationships have brought with them notable effects and changes in people's way of life and thinking, which will not instantly disappear as soon as the epidemic ceases, but on the contrary, could persist far beyond the eradication of the causes that produced them. Therefore, in this paper we aim to draw attention to some of the most important changes in people's behaviours and way of life in the context of the crisis caused by the COVID-19 pandemic.

\section{INSIGHTS ON THE COVID-19 PANDEMIC}

\subsection{Insights on evolutionary strategies and causes of the crisis}

A particularly interesting perspective on the crisis is the one founded on ideas derived from the philosophy of Darwinian and neo-Darwinian evolutionary biology, which underlie contemporary biological anthropology, but also other scientific fields such as sociobiology, behavioral ecology or evolutionary psychology. In this context, Professor Michael S. Gazzaniga, Director of the SAGE Center for the Study of Mind at the University of California, Santa Barbara, requested and then published in a collective paper he edited the views of twelve researchers from various fields which have as a common ground in these neo-Darwinian evolutionary methodological foundations, regarding the way in which the current epidemiological crisis, a phenomenon that is not at all new and never seen before in the history of our species, has radically altered people's lives and the fundamental structures of society. An evolutionary perspective, he believes, allows us to understand certain issues regarding human nature, the nature of the virus we now have to face, but also the interaction between the two and the evolutionary strategies that each party puts into play, which can help us design more effective ways to meet this and similar challenges that will arise in the future (Gazzaniga, 2020).

In this context, an interesting perspective is offered by evolutionary psychologist Athena Aktipis from Arizona State University, and medic Joe Alcock, from the Department of Emergency Medicine, University of New Mexico, according to whom the infection with the SARS-CoV-2 virus could have as consequences not only a whole series of physiological symptoms specific to the disease, but also certain changes in the patient's social behaviour, having as consequence a surge in the spread of the virus by increasing the chances of its transmission to other people. This possibility derives from the existence of evolutionary pressures that positively select any mechanism by which a virus or parasite can cause behavioural changes in its host, due to which its transmission accelerates: a variety of virus that has this effect will survive much more efficiently than one that it does not favour its own spread to the same extent.

According to Aktips and Alcock (cited in Gazzaniga, 2020), there are two ways in which the SARSCoV-2 virus causes these behavioural changes that are beneficial to it. On the one hand, such 
behaviours can be induced given the way in which the infection occurs, because in the incubation phase, in which its carrier becomes highly contagious, the symptoms and debilitating sickness are missing, so that when the disease is transmitted with maximum efficiency, the patient feels good and social interactions are normal. Given that the best evolutionary strategy for a virus is to delay the onset of debilitating symptoms until after the phase when transmission is maximum, so as not to induce behaviours that socially isolate the infected, the two scientists argue that this virus is spreading so quickly precisely because its specificity is to be extremely contagious before the onset of symptoms associated with the disease.

The second way in which the virus can influence the social behaviour of its host to promote its spread is to cause behavioural disorders analogous to manic-depressive syndrome, in the form of alternating periods of social inactivity, fatigue and depression (when the virus is more aggressive and the immune system concentrates all the body's resources to counteract the attacks) with intervals of intense social activity, good physical condition and expansive mood (when the virus is less active and allows the immune system to regain control). Although there are still no systematic studies on how the SARS-CoV-2 virus alters social behaviour in this way, the phenomenon has been observed in other viruses, such as HIV, the 1918 influenza virus or the Borna disease virus (Gazzaniga, 2020: 27768-9), which allows us to hypothesize that this pattern could be found here as well, especially given that there is ample evidence that the SARS-CoV-2 virus has a predilection for infecting neural tissues and thus causes a multitude of neurological symptoms. The latter can be the result of evolutionary adaptations of the virus itself, residual products of its action, consequences of the host's response to the presence of the virus, or a combination of them all. Under these conditions, future research is needed to systematically investigate these behavioural, psychological and neurological symptoms, to see to what extent the virus is able to effectively exploit the two ways in which it can alter human behaviour in order to promote its spread.

Another interesting observation concerning the interaction between the mechanisms of viral infection and human behaviours specific for the context of current epidemiological crisis belongs to Barbara N. Horowitz, professor of medicine at the Division of Cardiology, University of California (cited in Gazzaniga, 2020). The rigorous quarantine measures imposed during the pandemic have not only resulted in a limitation of the spread of the disease, but also in certain less desirable side effects. These include reducing the normal exposure of the human body to various pathogens that occur naturally in situations where social interactions are not limited in any way and human behaviours such as neophilia or limited risk taking are natural. Normal exposure to various pathogens in early life stages decisively determines the development of the immune system, which will later protect the mature body against other infections, but also of the intestinal microbiome, which is essential for the normal functioning of digestion function and for maintaining a normal metabolism. Under these novel artificial circumstances, the current generations of children and young people suffer the most, because quarantine has stopped all categories of physical interactions between them and their peers, and thus deprives them of natural contact with pathogens absent in the family environment, which can lead to the advent of a future generation of adult people with serious deficiencies of the immune system and metabolism in general.

One category of social interactions that suffers particularly from quarantine and physical distancing measures, as evolutionary psychologist David M. Buss (cited in Gazzaniga, 2020) observes, is that related to human reproductive behaviours, which normally exhibits a fairly high diversity of mating strategies, from long-term pair-bonding to casual sex. In the new social context, the perspectives for short-term sexual partnerships are especially limited, because any new sexual partner is potentially a carrier of the virus, and therefore a vector spreading the disease, so that this type of relationship will be limited by the risks that are associated with them. However, people who routinely adopt risky reproductive strategies, such as short-term relationships, frequent partner change, and have a large number of partners, will once again be inclined to take risks, and thus have the potential to become major spreading vectors of the virus. 
The alternative strategy, i.e. the formation of long term couples, seems more attractive in these conditions, but it is also severely disturbed by the fact that isolation and quarantine measures significantly reduce the chances of meeting suitable partners for such relationships. People in this situation are forced to replace normal physical interactions with virtual ones, taking place online, which makes it much more difficult to correctly estimate the qualities of a potential partner, such as emotional stability, honesty or intelligence, a predicament that makes people to interpolate imaginary positive values, and thus to idealize the qualities of the hypothetical partner and consequently to build unrealistic expectations about her/him.

To these impediments that stand in the way of implementation of various reproductive strategies one can add the fact that people generally believe the current social and economic circumstances to be risky and affected by uncertainty, so they will be much more reluctant when it comes to having children (Gazzaniga, 2020: 27770). Therefore, in the medium and long term it is very likely that we will see a dramatic decline in birth rates, which will, in turn, generate cascading negative economic and social effects.

\subsection{Insights on the social features and causes of the crisis}

The pandemic crisis does not bring significant changes only in what concerns the way interpersonal relationships take place in the context of reproductive behaviours, but it has effects that are felt in all kinds of interactions that take place in a society, significantly affecting the way in which people relate to their fellow human beings. For example, argues Paul Bloom, professor of psychology and cognitive science at Yale University (cited in Gazzaniga, 2020), one admits that in most situations, when an entire society goes through a period of crisis that affects all its members, there is an increase in the level of social solidarity, a multiplication of altruistic behaviours and helping gestures, motivated by an increase in empathy and compassion towards those in difficulty. In principle, those who consider this to be a natural manifestation are of the opinion that the motivations that cause people to act in this way pertains to human nature itself, seen as essentially pro-social and altruistic, and certain critical circumstances make the conventions and constraints of ordinary life in capitalist society disappear, allowing this beneficial human nature to emerge more easily.

In the context of the current epidemiological crisis, however, things are not as clear, and there are certain somewhat oxymoronic aspects, such as the phenomenon of internalizing the rules of physical distancing and isolation from other members of society, which are presented as the most explicit manifestation of social solidarity, of personal concern for peers. In other words, caring for others and for their wellbeing causes people to distance themselves from their fellows and voluntarily give up any contact with them, which is a paradoxical idea, given the essentially social nature of human being. If the idea seems contradictory from a logical point of view, from an empirical point of view the situation is also not much different, because there is still no serious evidence in support of the idea that distancing is really motivated by altruistic reasons, and not by the concern for one's own safety or for that of the close family members.

Moreover, Bloom points out, in the context of the current crisis, for now there is not enough evidence for the idea that in these difficult circumstances one sees indeed an increase in the degree of altruism, compassion, empathy and concern for the fate of others, compared to what happens under normal conditions. It seems that people resort to acts of assistance of those in need rather motivated by moral and not emotional reasons, considered after a rational assessment of the situation, conducing them to the conclusion that this is the right thing to be done. On the other hand, there is fairly consistent evidence that the current crisis situation does not contribute at all to strengthening social solidarity, but rather to creating social divisions or deepening existing ones, as is the case with the social polarization produced by the mask wearing rules, by rules of access to public places or social segregation measures of those vaccinated and those who do not want to be vaccinated. This, Bloom believes, could be explained by the fact that people are social beings, and 
in the present crisis precisely social relations are most affected by quarantine measures, so that real, and not virtual relations between people, the same that generate compassion and altruism are no longer possible, and the consequences are negative and dramatic (Gazzaniga, 2020).

Not only the relationships between individuals and the values that regulate and structure these relationships are important in the context of the current crisis, but also the systems of values and norms that determine the cultural specificity of each society. Thus, Michele Gelfand, Professor of Psychology and Organizational Behavior at Stanford University, cross-cultural management expert, builds her view on the idea that human groups establish systems of social norms that allow them to successfully cope with the challenges posed by external evolutionary pressures. These rules are necessary to ensure the coordination of the actions of all members of the group in difficult conditions and also to control the tendencies of some individuals to take advantage of the benefits of membership without paying the costs, or in other words social free-riding. From an evolutionary point of view, it can be predicted that those human groups or societies that throughout their history have frequently faced crises such as natural disasters, epidemics, scarcity of natural resources, external attacks and invasions or demographic pressures, and they have nevertheless survived, will have stricter and tighter systems of social rules and values, which punish more severely any violation and deviation from the norms. In turn, social groups that have not met serious and harsh challenges tend to have looser and more permissive systems of social rules. Models based on principles derived from game theory allow us to make predictions about how these two categories of human societies will cope with the crises they will have to face in the future (Gelfand, 2018).

In the context of the current pandemic crisis, it has been proved that the predictions are corroborated by experience, i.e., those societies that have tighter systems of social norms, such as China, Japan or South Korea have proven to be more capable to take efficient measures, thus limiting the spread of the virus and reducing the number of victims. By contrast, societies in which the system of social rules is less restrictive, such as the United States, Brazil or Italy, have failed to keep the contagion under control and limit the number of victims (Gazzaniga, 2020: 27772-3). Members of these societies do not have the past experience of serious threats, which is why they always tend to underestimate the danger and risks, and on the other hand they value individual freedom more than respect for the rules, and therefore tend to oppose the adoption of regulations that may limit the magnitude of the pandemic. Politicians in such societies are also reluctant to take action and implement measures to limit personal freedoms, fearing not to upset their electorate, so the response to the challenge posed by the COVID-19 epidemic in these societies has been delayed, timid and confusing.

\subsection{Understanding the social character of the crisis}

Although the social character of the COVID-19 pandemic is not directly denied, it could hardly be said that it is fully understood by specialists in the first line of action, called to find viable and rapid solutions, such as those in the medical, economic or political field. And this is not because sanitary, political and economic measures would not have their relevance, but because a crisis of such magnitude and depth needs a better understanding of human behaviour and, in particular, of the mechanisms and levers of its change, necessary in order to produce the developments claimed by experts to be the panacea for the crisis. As the British Financial Times journalist Gillian Tett (2021) convincingly argues, presenting information from the 2014-2015 "Ebola crisis", stopping the spread of the disease, or "disease containment", is far from a goal that can only be achieved through "cold" actions, designed by health experts and supported by political factors. Moreover, the misunderstanding of the social aspects of any crisis leads to its deepening and even to consequences that are difficult to anticipate and counteract.

Although the fear of contracting a potentially lethal pathogen can cause some individuals to change their behaviours, many examples around the world show that individuals may manifest strong resistance to change and that the anxiety caused by this change, sometimes translated as giving up 
social interaction, customs and traditions, is equivalent to a "social death", hardly bearable by anyone.

For example, in the "Ebola crisis" of 2014-2015, measures taken by international organizations and national authorities in Sierra Leone to stop the spread of the virus had the opposite effect, making them ineffective and even radicalizing the local population. Instead of following the sanitary rules imposed by authorities, the infected people fled the specially arranged isolation centres, sometimes showing violence against the medical staff, and the locals continued to take care of their affected relatives at home and, in case of death, bury them strictly observing the specific rituals, although they were a means of spreading the virus. If the deceased were buried by specialized personnel without the participation of family members, the bodies were later exhumed, to be re-buried, in secret, according to custom, which involved touching and even kissing the deceased (Tett, 2021). The fear generated by not respecting traditions and not fulfilling social roles was stronger than the fear of contracting the virus, because, according to local beliefs, the virus killed only the body, while not performing the funeral ritual killed the spirit (Goguen \& Bolten, 2017). The crisis was overcome when medical experts and political authorities understood and took into account issues related to social structure and culture, such as the attitude towards risk in general and towards death in particular, the atavistic beliefs of the population, as well as its need for social interaction and belonging (Tett, 2021).

For certain, each crisis is "special" because, in addition to the common core, it can manifest new features, so that previous experiences can be useless and therefore ignored. Moreover, the assumption that policies and measures to combat the COVID-19 pandemic have not taken into account the social nature of the crisis and the fact that top-down approaches are not always effective may be erroneous. However, a simple element circulated since the beginning of the crisis may lead to the conclusion that the social aspects of the crisis have been, if not completely misunderstood, at least underestimated. One of the expressions used by experts and ordinary people alike, as a measure to limit the spread of the virus and, implicitly, the effects of the pandemic, was that of "social distance", contacts or social interactions becoming the focal point of prevention efforts (Connell, 2020). This, in spite of the fact that people around the world, although they understood the need to maintain physical distance, tried by all means to avoid social distancing and to maintain closeness to others, keeping in touch with members of their social networks. In the view of the American sociologist Emory Bogardus, the author of the social distance scale, the term refers to the emotional reactions of individuals to other individuals or groups, which reveal one's "likes" or "dislikes" in one's interpersonal or group relationships (Bogardus, 1947). In other words, "social distance" measures the quality and intensity of interpersonal relationships and the attitude of individuals towards others, the urge to maintain social distance meaning, in this sense, an invitation to cultivate a feeling of antipathy towards peers.

Without claiming that such an urging, obstinately promoted by medical and political authorities around the world, is the source of inter- and intra-societal polarization, it is worth mentioning that incidents have been reported in some parts of the world suggesting an increase in verbal and even physical violence against "others", members of other groups, usually associated with the "origin" of the pandemic or the "causes" of its prolongation (Fuentes, 2020). However, such manifestations lead to the weakening of social cohesion and to the erosion of trust in state institutions, at a time when solidarity, prosocial behaviours and emotional support are needed.

In times of crisis, state institutions, no matter how strong and respected, are rarely able to develop and implement, on their own, the necessary measures to counteract the psychological and social effects felt by individuals and communities (Matthewman \& Huppatz, 2020), such as fear of isolation and the need to belong; the loss of individual rights and freedoms, such as the right to free movement, the right to family life or freedom of expression; or uncertainties about the causes and evolution of the pandemic and the feeling of helplessness (Saladino et al., 2020). 
Humans are, par excellence, social beings, who need interaction with others, this need for social inclusion, manifested by belonging to various groups, interpersonal relationships, or communication being fundamental and above many other needs, including the basic ones. In their long history, people have relied on each other for survival, with exclusion from the group and lack of social contact equivalent to a death sentence. For this reason, people have developed psychological mechanisms and behavioural strategies to ensure their affiliation with groups and social inclusion, ostracism being costly in terms of survival (Kanazawa, 2012). Moreover, the neural manifestations of social separation show that social pain, caused by exclusion from the group or loss of contact with others is similar to physical pain, activating the same brain regions, suggesting the adaptive value of social ties and mechanisms of social attachment (Eisenberger et al., 2003).

Therefore, social isolation and distancing can have negative effects on human psychology and sociality, with the threats of the COVID-19 pandemic being not only biological but also social, with a major impact not only on the body but also on the mind and community. As biological anthropologist Agustín Fuentes (2020) argues, relationships with others and social connections fundamentally influence the physical and mental health of individuals, having a major role in the functioning of neurobiological systems, endocrine system or immune system. Thus, giving up sociability and involvement in social activity, which lead to physiological and psychological depression, decreased immune function or gastrointestinal disorders and cognitive difficulties (Fuentes, 2020) is not a solution, and can have equally devastating effects on the health of the individual such as the infection itself.

Given the importance of the social aspects of any pandemic, the difficulty of changing human behaviours, even when life depends on it, but also the possibility of ignoring the lessons learned from previous crises by political factors, it is worth mentioning the insights of the medical anthropologist Linda Whiteford (2020), who suggests that the measures developed could work if four conditions were met, namely:

1) empowering individuals and involving them directly in combating the pandemic by clearly specifying the link between behavioural changes requested by authorities and their own interests, by raising awareness on the one-to-one relationship between the common and the individual good, and also the consequences of their actions on both personal and community welfare;

2) developing transparent and accessible instruments for measuring behavioural changes and their effects, by discovering the cultural specificities and translating them into units of measurement that reflect local meanings;

3) involving community in the exchange of resources and information, but also in the implementation of measures that can lead to immediate changes, by reducing the feeling of social isolation and focusing on the need to belong;

4) identifying a time frame of the crisis, capitalizing on people's ability to change their behaviours and adapt to difficult situations when there is a time horizon and when uncertainty about the future is reduced.

While not guaranteeing that they will work in the current COVID-19 pandemic, such measures or conditions have the potential of reducing uncertainty and sentiments of uselessness, making the psychological and social effects of the crisis more bearable and, potentially, the actions taken to combat the crisis more effective.

\section{CONCLUSIONS}

The COVID-19 pandemic, while not new in the long history of human species, has generated a complex and multi-faceted crisis, which might lead to the change of the humankind and its social organization and structure for good. Before jumping to the widespread opinion that any crisis is a source of opportunities that should be turned to advantage, both people and institutions have to deal with the challenges it poses to their very existence. 
A good start for dealing with challenges and, eventually, hoping for a viable solution, is to bear in mind that a pandemic is essentially and primarily social in both its causes and consequences, being directly influenced by the fundamental features that define the human species, such as the tendency to interact with other people or the need to belong. Not taking into account the social aspects of the crisis is not an option, as suggested by previous experiences with pandemics or health crisis. Any answer to the crisis would require major changes in human behaviour, changes that might not be possible unless they are understood in a cultural context.

\section{REFERENCES}

Bălan, S. \& Vreja, L. O. (2013). The Trompenaars' Seven-Dimension Cultural Model and Cultural Orientations of Romanian Students in Management. Popa, I., Dobrin, C. \& Ciocoiu, C. N. (Eds.). Proceedings of the 7th International Management Conference: New Management for the New Economy. Bucharest, Editura ASE.

Bogardus, E. S. (1947). Measurement of Personal-Group Relations. Sociometry, 10(4), 306-311. DOI: $10.2307 / 2785570$.

Connell, R. (2020). COVID-19/Sociology. Journal of Sociology, 56(4), 745-751. DOI: $10.1177 / 1440783320943262$.

Eisenberger, N. I., Lieberman, M. D. \& Williams, K. D. (2003). Does Rejection Hurt? An fMRI Study of Social Exclusion. Science, 302, 290-292. DOI: 10.1126/science.1089134.

Fuentes, A. (2020). A (Bio) anthropological View of the COVID-19 Era Midstream: Beyond the Infection. Anthropology Now, 12(1), 24-32. DOI: 10.1080/19428200.2020.1760635.

Goguen, A. \& Bolten, C. (2017). Ebola Through a Glass, Darkly: Ways of Knowing the State and Each Other. Anthropological Quarterly, 90(2), 429-456. DOI: 10.1353/anq.2017.0025.

Hookway, C. (1992). Peirce: The Arguments of the Philosophers. London and New York: Routledge.

Kanazawa, S. (2012). The Intelligence Paradox. Why the Intelligent Choice Isn't Always the Smart One. New Jersey: John Wiley \& Sons, Inc.

Lupton, D. \& Willis, K. (2021a). The COVID-19 Crisis: Social Perspectives. London and New York: Routledge.

Lupton, D. \& Willis, K. (2021b). Covid Society: Introduction to the book. Lupton, D. \& Willis, K. (Eds.). The COVID-19 Crisis: Social Perspectives. London and New York: Routledge.

Mair, V. H. (2009). Danger + opportunity $\neq$ crisis: How a misunderstanding about Chinese characters has led many astray. Available from http://pinyin.info/chinese/crisis.html, accessed on September 12, 2021.

Matthewman, S. \& Huppatz, K. (2020). A sociology of Covid-19. Journal of Sociology, 56(4), 675-683. DOI: $10.1177 / 1440783320939416$.

Peirce, C. S. (1935). Collected Papers of Charles Sanders Peirce, Volumes V and VI: Pragmatism and Pragmaticism and Scientific Metaphysics, edited by Hartshorne, C. \& Weiss, P. Cambridge, MA: Harvard University Press.

Saladino, V., Algeri, D. \& Auriemma, V. (2020). The Psychological and Social Impact of Covid-19: New Perspectives of Well-Being. Frontiers in Psychology, 11, Article 577684. DOI: 10.3389/fpsyg.2020.577684.

Shapiro, F. (Ed.). (2006). The Yale Book of Quotations. New Haven and London: Yale University Press.

Tett, G. (2021). Anthro-Vision. A New Way to See in Business and Life. New York: Avid Reader Press / Simon \& Schuster.

Trompenaars, F. \& Hampden-Turner, C. (2021). Culture, Crisis and COVID-19: The Great Reset. Newcastle upon Tyne: Cambridge Scholars Publishing.

Whiteford, L. M. (2020). A Room with a View: Observations from Two Pandemics. Anthropology Now, 12(1), 7-10. DOI: 10.1080/19428200.2020.1760630. 